Originalveröffentlichung in: Between the Cataracts. Proceedings of the 11th Conference of Nubian Studies, Warsaw University 27 August - 2

September, Warschau 2010, S. 781-782

\author{
Angelika Lohwasser
}

\title{
KUSHITE QUEENS AS REPRESENTED IN ART ${ }^{1}$
}

Any investigation of the costume of the queens of Kush brings up immediately remarkable differences between depictions of the Napatan and of the Meroitic period. Let me show first the costume of Napatan queens [Fig. 1] and then that of the Meroitic kandakes and queens.

In the former case, a large shawl was wrapped around the body below the armpits or around the hips. A second shawl, which could be fringed or decorated with woven stripes, was worn over the first. Sometimes women draped a sash over the shoulder. A small tab-like element hangs below the hem of a dress and reaches the ground. This diagnostic element has been described as a "little tail". Sometimes there are fine ridges on its surface and in very few cases it resembles a simple line. However, this iconographic feature is not restricted to depictions of royal women. Granted, the bull's tail of kingly regalia was inappropriate for a woman; nevertheless, the "little tail" is indeed reminiscent of an animal's tail. The bushy shape, which occurs in most depictions, and the ridges, which could have been intended to imitate the appearance of fur, can be cited in favor of this proposal. Possibly Kushite women tied an animal tail, as an amulet insuring fertility, to their knee or calf, and it hung down below the dress worn over it.

The wigs worn by Egyptian royal women exhibit considerable variety. By contrast, Kushite women did not wear wigs. Depictions of their natural bobbed hair are sometimes detailed to show small, tight curls. In one of the depictions of Wedjarenes and in the sole representation of Meritamun, little braids hang down from the back of the head to the neck, terminating in decorative little tassels or tiny beads.

The "Kushite headdress", unusual headgear known only from representations of Kushite women, consists of as many as four components, shaped like tiny figures of goddesses or papyrus umbels, attached to a fillet. Band-like elements spring upward from these "supports" to arch down over the back of the head. Perhaps the "bands" are intended to depict feathers. Hofmann
(1977) would interpret this headgear as an element identifying a member of the royal harem. Kendall (1982: 25), also, presumes that different kinds of headdresses reflected differing status among royal women. Only royal women of higher rank were entitled to wear crowns and the uraeus; for royal women of lower rank, the Kushite headdress was used.

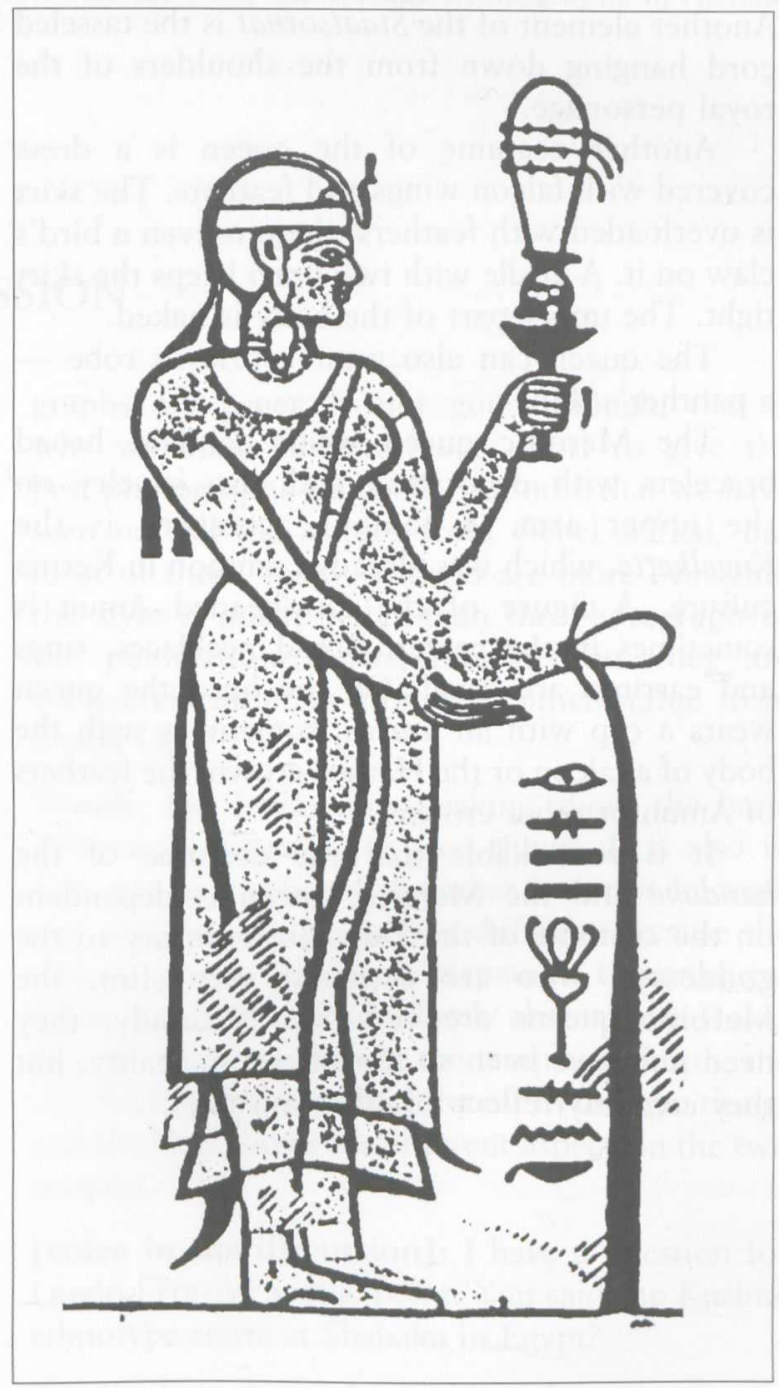

Fig. 1. Pelcha as represented on the Stela of Nastasen (Egyptian Museum Berlin, inv. no. 2268; drawing K.-H. Priese)

1 This is the introduction to the discussion as presented at the Conference. For detailed studies, see Lohwasser 1999; 2001; 2006; Török 1990; 1987. 
Kushite royal women are seldom depicted wearing the vulture headdress. Often a fillet that served to secure a lotus blossom at the forehead and/or a uraeus was tied around the head. The most frequently documented headgear consists of double plumes with sun disc and cow horns. The headdress is short and squat by comparison with its Egyptian prototype; it looks already meroiticized.

The costume of the Meroitic kandake is similar to that of the king [Fig. 2]. First, there is the so-called Staatsornat. A long underdress can be seen in the representation from the Lion temple at Musawwarat el-Sufra; it is no longer visible in the later Lion temple of Naga. On top of this there is a coat with pleats and fringes at the bottom and along the vertical edge. A shawl with long fringes is thrown over the right shoulder. The fringes are shorter in the early Meroitic period and longer in the middle Meroitic period. Another element of the Staatsornat is the tasseled cord hanging down from the shoulders of the royal personage.

Another costume of the queen is a dress covered with falcon wings and feathers. The skirt is overloaded with feathers, there is even a bird's claw on it. A girdle with two uraei keeps the skirt tight. The upper part of the body is naked.

The queen can also wear a priest's robe a panther's skin.

The Meroitic queen wears sandals, broad bracelets with decoration and also jewelry on the upper arm. A famous accessory is the Kugelkette, which was already common in Kerma culture. A figure of the ram-headed Amun is sometimes in the center. Broad necklaces, rings and earrings are usual. On the head the queen wears a cap with an uraeus, sometimes with the body of a falcon or the Hathor-crown, the feathers of Amun or other crowns.

It is remarkable that the costume of the kandake and the Meroitic queen is dependent on the costume of the king. But contrary to the goddesses, who are depicted very slim, the Meroitic queens are very fat. Naturally, they need not have been so monstrous in reality, but they certainly reflect a kind of ideal.
To conclude, the Meroitic period was characterized by many different costumes, whereas the variability in the Napatan period was much smaller. The robes of the Meroitic queen were influenced very much by the king's costume, but the ample body was shown very clearly.

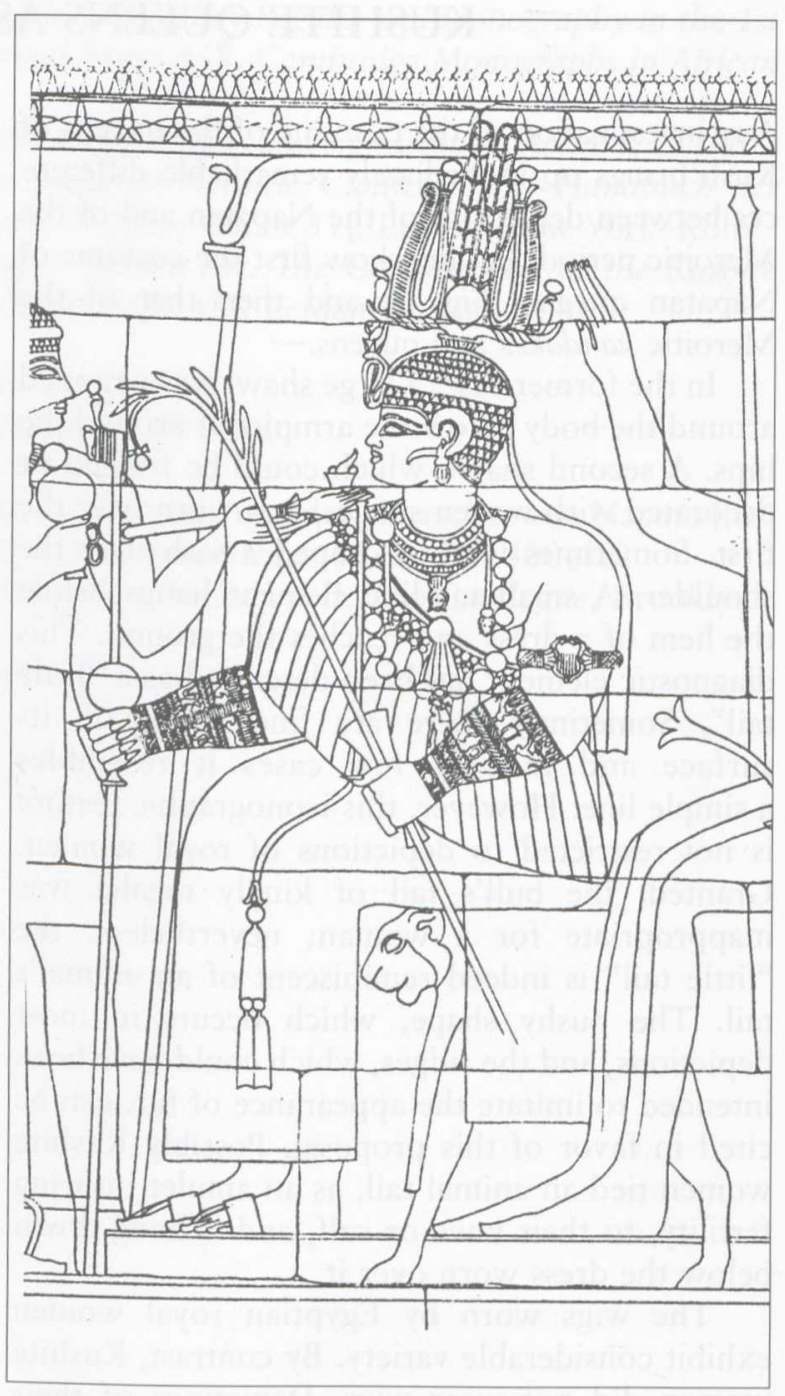

Fig. 2. Amanishakheto as represented in her funerary chapel in Beg. N 6 (after S.E. Chapman, D. Dunham, Decorated Chapels of the Meroitic Pyramids at Meroë and Barkal. The Royal Cemeteries of Kush III, Boston 1952: Pl. 16B) 